\title{
Cláusulas relativas em Gavião de Rondônia
}

\author{
Relative clauses in Gavião of Rondônia
}

Resumo: A língua dos Gavião de Rondônia constrói cláusulas relativas por meio de nominalização sintática, usando uma de duas partículas, mát 'nominalização concreta' ou méne 'nominalização abstrata', que são derivadas diacronicamente de pronomes de discurso. As cláusulas nominais assim construídas podem ou não ter um núcleo interno, que, se ocorre, não é marcado como tal, criando uma certa ambigüidade. A cláusula nominalizada pode modificar um radical nominal seguinte, que funciona como núcleo externo. Cláusulas relativas e cláusulas complementos não são construções distintas nesta língua. A significação tipológica destas construções é discutida.

Palavras-chave: Cláusulas relativas. Gavião de Rondônia. Nominalização. Cláusulas complementos.

Abstract: The language of the Gavião of Rondônia constructs relative clauses by syntactic nominalization, using either of two particles, mát 'concrete nominalization' or méne 'abstract nominalization', which are derived diachronically from discourse pronouns. The resulting nominal clause may or may not have an internal head, which, if it occurs, is not marked, leading to a certain degree of ambiguity. The nominalized clause can modify a following noun stem, which serves as an external head. Relative clauses and complement clauses are not distinct constructions in this language. The typological significance of these constructions is discussed.

Keywords: Relative clauses. Gavião of Rondônia. Nominalization. Complement clauses.

I Museu Paraense Emílio Goeldi. Pesquisador. Belém, Pará, Brasil (moore@amazon.com.br).

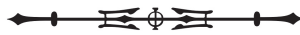




\section{INTRODUÇÃO}

A familia lingüística Mondé, do tronco Tupi, contém três línguas: Suruí de Rondônia, Salamãy (que tem duas semifalantes conhecidas) e a língua que é constituída dos dialetos, mutuamente inteligíveis, falados pelos Gavião, Zoró, Cinta Larga e Aruá. A população atual dos Gavião conta com cerca de 400 a 450 pessoas, das quais quase todas falam a língua nativa. A língua dos Gavião apresenta nominalização sintática que produz construções que se traduzem como cláusulas relativas ou como complementos sentenciais. Comrie e Horie (1995) observam que nem todas as línguas têm uma distinção entre cláusulas relativas e cláusulas complementos, citando evidências do Japonês e do Khmer. Nesse sentido, a língua Gavião exemplifica esse fenômeno. Em Gavião, duas partículas derivam nominais: mát 'nominalização concreta' e méne 'nominalização abstrata'. No dialeto dos Aruá, a forma para nominalização abstrata é máne, que sugere, em sua etimologia, má+ve, em que o sufixo //ve// (que ocorre com verbos e adjetivos também) tem o sentido 'nominalização abstrata'. Parece que a nominalização sintática, através destas duas partículas, é uma inovação na língua dos Gavião, Zoró, Cinta Larga e Aruá, não compartilhada pelas outras duas línguas da familia. As partículas de nominalização sintática provavelmente têm como origem os pronomes de discurso homófonos.

\section{PRONOMES DE DISCURSO}

Os dois pronomes de discurso, mát (com plural máày) 'pronome de discurso concreto' e méne 'pronome de discurso abstrato', sempre ocorrem no início de sentença. Esses pronomes, como outros em Gavião, podem ser o núcleo de um SN e não podem modificar nominais que os seguem. Esses pronomes referemse às frases que imediatamente os precedem, como pode ser observado nos exemplos de (1) a (4).

(1) mát sóòt va bó pạ-ága pazé-èy tá eé-na aquela fermentada tomar foco 1 pi-Aux outro-pl com aquela-maneira 'Fermentada assim nós tomamos com os outros.' (Frase anterior: 'Aí fermenta.' (chicha))

(2) mát ka bó tá-máà ci-ko-e ábemáá teé-á aquele em foco 3p-Aux:passado 3s-boca-abstrata (=words) seguir continuando-fim 'Eles estavam aí [naquele] repetindo as suas palavras.' (Frase anterior: "'Onde eu entro para tomar chicha com vocês?" ele perguntou.'

(3) "méne ajálá bó máà a-ti kaj-á" kí-ip aquilo deixar foco (3s)-Aux:passado 3c-mãe envolver-fim evidência-passado 'Ele deixou aquilo com a sua mãe.'

(Frase anterior: 'Ele moqueou muitos pássaros antes de ir a sua viagem para buscar escuridão. Os pássaros serão sinais da sua volta.')

(4) "méne mi paní pa-vít aka kị̂á bó vit aquilo usar 1pi:Aux:deixar 1pi-comida matar de:novo-fim foco comida

$\begin{array}{lll}\text { aká-ày } & \text { máà } & \text { kí-á } \\ \text { matar-agente:pl } & \text { Aux:passado } & \text { de:novo-fim }\end{array}$

'"Vamos matar nossa comida daquela maneira de novo", os caçadores disseram.'

(Frase anterior: 'Aí ele fez mágica para a caçada deles falhar.')

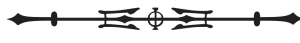


Note que, no exemplo (1), mát refere-se ao sujeito da frase anterior, já no exemplo (2) refere-se a alguma coisa entendida, mas não presente explicitamente na frase anterior. No exemplo (3), méne refere-se aos pássaros, em sua capacidade de indicar sinais, que são o objeto da frase anterior. No exemplo (4), méne refere-se a uma maneira de caçar, que é entendida, mas não mencionada na frase anterior.

Como é possível perceber, esses pronomes não possuem necessariamente um SN correferencial na frase anterior. $O$ ouvinte tem de inferir a referência do contexto. Essa mesma ambigüidade (ou flexibilidade) caracteriza as nominalizações formadas por mát e méne no seu papel de partículas nominalizadoras.

Como hipótese diacrônica, os pronomes de discurso tornaram-se partículas nominalizadoras. Segundo Noonan (1985), complementizadores freqüentemente são derivados de pronomes, como no caso do complementizador that em inglês, que é derivado do pronome that. $O$ caso Gavião seria a imagem espelho dos complementos introduzidos por that em inglês, que precede a cláusula, uma vez que tanto mát quanto méne seguem o material a que se referem, como pronomes, e o material que nominalizam (sintagmas verbais e cláusulas). 0 esquema representa essa extensão das funções de mát e méne:

discurso imediatamente anterior - mát/méne > SV ou cláusula - mát/méne

A partícula mát aparece também em conjunções, como descrito em Moore $(1989,1984)$.

\section{NOMINALIZAÇÃO DE SINTAGMAS VERBAIS}

No seu papel de nominalizadores, mát e méne são consideradas partículas, uma vez que há um padrão geral em Gavião de derivação sintática por meio de partículas e nenhum nome, pronome ou demonstrativo pode formar uma construção com um SV que o precede nessa língua. O escopo das partículas nominalizadoras é o sintagma verbal, não o verbo, pois partículas com escopo de sintagma, por exemplo óòp 'negativo' ou terè 'verdadeiro', podem ocorrer entre o verbo e a partícula nominalizadora. As nominalizações concretas são substantivos, lugares, eventos etc. As nominalizações abstratas são fatos, razões ou maneiras. Palavras que se traduzem como posposições em Gavião são formalmente verbos transitivos, já que têm a mesma distribuição e podem ser negadas, intensificadas ou nominalizadas da mesma maneira que verbos. Alguns exemplos de nominalização de SVs (sublinhados) são expostos nos exemplos (5) a (8).
(5) "me-tá
$\underline{\text { mát }}$
$\mathrm{ka}$
téét
méè $\mathrm{y}-\mathrm{ka}$
2p-morar nominlzn:concreta em
exato
2p-(Aux:imperat:definido)-ir
paágáá
kára-ále-á"
máà
tá-kay-á
(3s)-abrir ainda-futuro-fim (3s)-Aux:passado 3p-envolver-fim
" "Vão abrir onde vocês moram", ele falou para eles.'

(6) natáó ká mát

Natal em nominlzn: concreta

'Dá as fotos de Natal para nós.' sep ma-'óló ęèt tó-koy-á

folha:obj trans-vir 2s-(Aux:imperat:definido) 1pe-para-fim

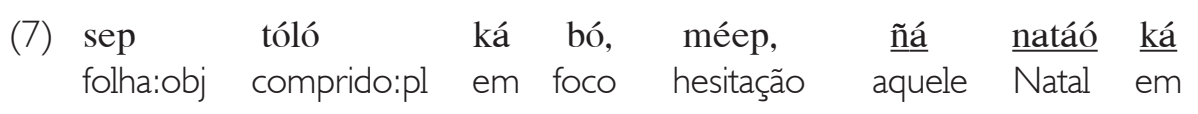

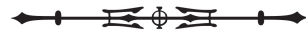


$\begin{array}{lll}\text { méne } & \text { sé-e-na } & \text { kí-nap } \\ \text { nominlzn:abstrata } & \text { Aux:subjetivo-aquela-maneira } & \text { evidência-indef }\end{array}$

'É nas fotos compridas que têm fotos de Natal.'
(8) ọo té me-sá ạa sérék tá méne
neg não:afirm 2p-Aux:não:afirm esta (3s)-roupa com nominlzn:abstrata ver
'Você não está vendo como ela está com a roupa?' (grávida)

A nominalização é definida por Givón (1990) como "the process by which a prototypical verbal clause either a complete sentence (including the subject) or a verb phrase (excluding the subject) is converted into a noun phrase". Entretanto, as nominalizações sintáticas formadas por mát e méne não são sintagmas nominais plenos. A evidência disso é o fato de que estas nominalizações sintáticas, exposta no exemplo (9), como as nominalizações morfológicas, exemplo (10), podem modificar um radical de nome que as segue, o que é impossível para um sintagma nominal em Gavião, como o é em inglês (*these bricks house vs. brick house). As nominalizações sintáticas são consideradas aqui nomes sintáticos ou nomes barra-um - construções nominais maiores que nomes morfológicos, mas menores que sintagmas nominais. Em Gavião todas as categorias lexicais maiores têm projeções barra-um (MOORE, 1984). Dentro do sintagma, esses nomes sintáticos têm a mesma distribuição que qualquer outro nome, podendo, por exemplo, ser modificados por adjetivos que ocorrem em seguida. A modificação dos nomes sintáticos por radicais nominais que ocorrem em (9) é exatamente paralela à modificação desses radicais por nomes não-derivados, como no exemplo (11).

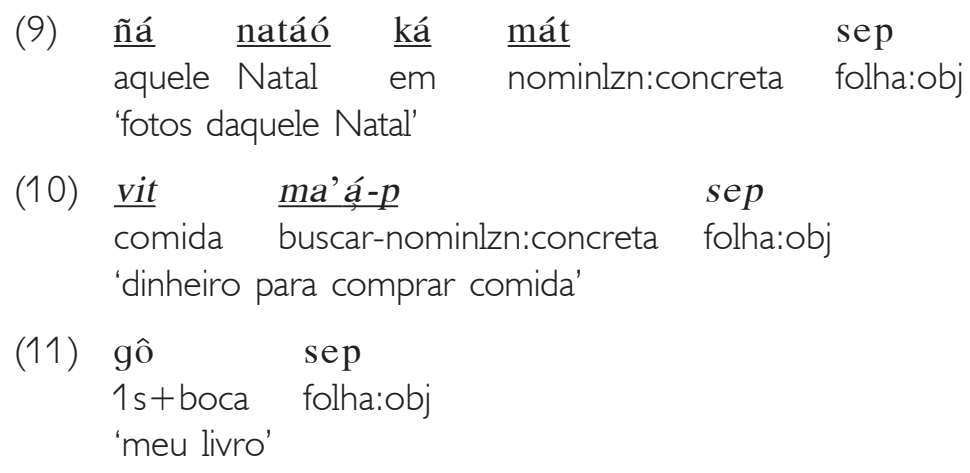

Construções do tipo vit ma'ạ́p em (10) são freqüentemente consideradas genitivos (NOONAN, 1985). Entretanto, em Gavião, essas construções também são nomes complexos e freqüentemente modificam radicais de nomes. Os exemplos de (9) a (11) são compostos e não-genitivos; o radical de nome, sep 'objeto na forma de uma folha', é um dos radicais de nome que podem ser modificados, mas nunca possuídos em Gavião (*gaáy sep 'folha da minha mãe'). As nominalizações podem também ser o primeiro SN de um apositivo, em que o outro membro do apositivo é um SN pleno, não somente um radical de nome, como no exemplo (12).

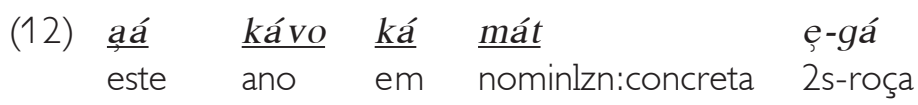

'sua roça deste ano'

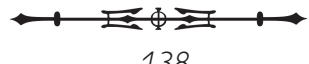




\section{NOMINALIZAÇÃO DE CLÁUSULAS}

Um tipo de cláusula subordinada, cujo auxiliar é marcado com o sufixo //-néè//, é sempre nominalizada por mát ou méne. Segundo Givón (1990), "In many languages, REL-clauses as well as verb complements and adverbial clauses are all nominalized, so that only main clauses have fully finite syntax". Este não é o caso das cláusulas nominalizadas de Gavião que têm as mesmas possibilidades de composição que outras cláusulas, exceto certas partículas que ocorrem somente na cláusula matriz. Nas nominalizações sintáticas, há três contrastes de tempo/aspecto marcados no auxiliar: não marcado, passado indefinido e passado definido. As cláusulas nominalizadas, como quaisquer outras cláusulas em Gavião, contêm um sujeito e um auxiliar e podem conter vários SVs e cláusulas encaixadas, passíveis de serem deslocadas. A cláusula nominalizada freqüentemente tem como núcleo relativo interno o sujeito da cláusula; porém o núcleo interno pode também ser um objeto ou, aparentemente, um genitivo. É possível também que a cláusula não possua um núcleo interno. Independente da existência de um núcleo interno em uma nominalização, pode existir ou não um núcleo externo. Os exemplos (13) a (17) apresentam cláusulas nominalizadas sem núcleo externo e com ou sem núcleo interno.

No exemplo (13), o núcleo interno é 'tábua de paxiúba', o sujeito da cláusula encaixada, e a nominalização está modificada pelo adjetivo 'em pé'.

$\begin{array}{cllllll}\text { (13) "eé bó pazé-ièy máà } & \text { Jóp } & \text { abí } & \text { palí } & \text { sábéè } \\ \text { aí foco } & \text { outro-pl Aux:passado barreiro ao:lado:de } & \text { paxiúba } & \text { tábua }\end{array}$

aí foco outro-pl Aux:passado barreiro ao:lado:de paxiúba tábua

\begin{tabular}{|c|c|c|c|c|c|}
\hline $\begin{array}{l}\frac{\text { ánéè }}{\text { (Aux:passado:definido)- }} \\
\text { nominal }\end{array}$ & $\begin{array}{l}\frac{\text { a-vé-pea }}{3 \text { c-intrans-bater: }} \\
\text { pl:obj }\end{array}$ & $\begin{array}{l}\underline{\text { mát }} \\
\text { nominlzn: } \\
\text { concreta }\end{array}$ & $\begin{array}{l}\text { picaá } \\
\text { em:pé }\end{array}$ & $\begin{array}{l}\text { mága-á" } \\
\text { colocar-fim }\end{array}$ & $\begin{array}{l}\text { kí-ip } \\
\text { evidência-passado }\end{array}$ \\
\hline
\end{tabular}

Em (14), o núcleo interno seria o sujeito de terceira pessoa e a cláusula nominalizada é o sujeito da matriz.

(14) pa-bábe ákinì mága óoòp saká-néè mát 1 pi-mão ver (3s)-fazer neg 3s:Aux-nominal nominlzn:concreta
sé-e-na
a-ma-kóbáá
kí-nap
Aux:subjetivo-aquela-maneira 3c-trans-aprender evidência-indefinida

'Quem não faz [cerâmica] aprende vendo as nossas mãos.'

Em (15) não há núcleo interno na cláusula, que é objeto do verbo 'usar'.
(15) "náapó tígi paá-néè náapó kávo ká méne aquele tempo:de 1pi-(Aux:passado:definido)-nominal aquele ano em nominlzn:abstrata
mi teé pa-máge-é-na kibal-é-na kí-á” mâá
usar contin 1pl-Aux-aquela-maneira dançar-aquela-maneira de:novo-fim 1s:Aux:passado
'Eu digo que nós vamos dançar de novo do jeito que fizemos naquele tempo no ano passado'.

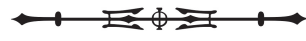


Em (16), a nominalização não tem núcleo interno e é objeto de 'em'.
(16) "é́-na
tá-máà
a-ma-ágạá,
a-kapạ́p
$\underline{m a-}-\underline{11}$
aquela-maneira
3c-trans-amanhecer
3c-escuro
trans-entrar
aá-néè
méne
ká-á"
kí-ip
3c-(Aux:passado:definido)-nominal nominlzn:abstrata em-fim evidência-passado
'Assim eles fizeram ficar de dia quando eles fizeram escuridão entrar de novo.' (i.e. dentro da vasilha)

No exemplo (17) a nominalização concreta não tem núcleo interno e possui o nome 'costas':
(17) “'jè
$\frac{\text { tá-kaypaà }}{3 p-c h a m a r}$
meé-néè
2p-(Aux:passado:definido)-nominal
mát
ábiït abi teé mâáa áá
costas:dimin lado:de
contin
1s:Aux: passado
(3s)-buscar-fim
máà
tá-kaj-a"
kí-ip
(3s)-Aux:passado 3p-envolver-fim
evidência-passado
'“Eu busquei eles atrás de onde você estava chamando eles", ele disse para eles.'
(Um homem explica para os outros onde ele achou os macacos.)

Nota-se que a interpretação da cláusula nominalizada em (17) é como um lugar, sem qualquer marcação explícita interna desta interpretação. Cláusulas nominalizadas em Gavião não têm relativizadores de localização ('onde'), maneira ('como') ou tempo ('quando').

Nos exemplos (18) e (19), as cláusulas nominalizadas têm um núcleo interno (nestes exemplos um objeto) e um núcleo externo idêntico ao núcleo interno. Estes casos são mais parecidos com a idéia clássica de uma cláusula relativa:

Em (18), o núcleo interno e externo é 'objeto com forma de uma folha'.
(18) natáó
ká eé-néè
$\frac{\text { sep }}{\text { folha:obj }} \stackrel{\text { igí }}{\text { tirar }} \quad \underline{\text { mát }}$ nominlzn:concreta
Natal em 2s-(Aux:passado:definido)-nominal
sep íkinì matẹée ęèt ķí-gáre-ále-á
folha:objeto ver causativo 2s-(Aux:imperat:definido) de:novo-ainda-futuro-fim
'Mostre para nós as fotos que você tirou no Natal.'

Em (19), o núcleo interno e externo é 'roupa'.

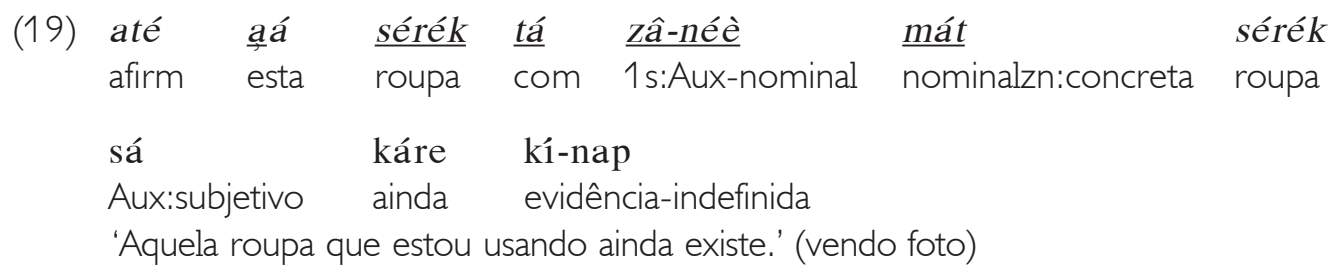

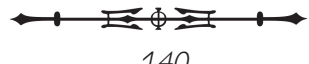


O uso de núcleos externos é um recurso que possibilita indicar um núcleo relativo, eliminando ambigüidade. Nominalizações abstratas podem ter núcleos internos e externos também, porém tais casos são raros por razões semânticas. Um exemplo permitido pelo informante é a construção (20):
(20) $\underline{\text { na }}$
natáó ká
eé-néè
paá-co î́í méne
sep
aquele Natal em 2s-(Aux:passado:definido)-nominal 1pl-foto tirar nominlzn:abstrata folha:obj 'As fotos que você tirou de nós naquele Natal'

Neste exemplo, o núcleo interno é '1 pl-foto' e o núcleo externo é 'objeto com forma de folha'.

Seguindo a "Accessibility Hierarchy" de Keenan e Comrie (1977), a expectativa seria de que sujeitos e objetos fossem mais facilmente relativizados do que outros argumentos das cláusulas encaixadas, o que parece ser o caso. A ocorrência de núcleos externos correferenciais deve facilitar relativização de argumentos internos. Além de sujeitos e objetos, os Gavião aceitam pelo menos alguns exemplos de construções nas quais um genitivo é o núcleo interno e externo, como exposto em (21):
(21) $\underline{\text { ávilì }}$
pí
ánéè
pa-záp $\quad \underline{\text { śtgi }}$
cachorro
rastro
(Aux:passado:definido)-nominal
1 pl-casa
perto

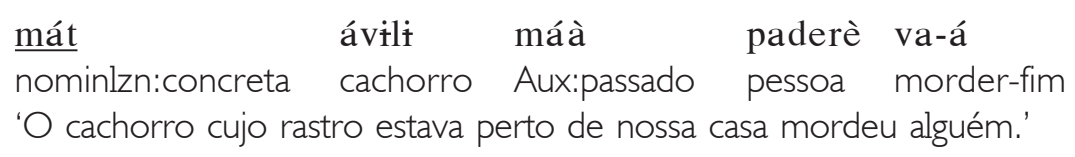

Como exemplo da ambigüidade das nominalizações que não têm marcação explícita de núcleos internos, considera-se o exemplo (22) que, segundo consultores Gavião, tem três interpretações:

(22) $\frac{\text { bay }}{\text { cobra }} \frac{\text { ánéè }}{\text { (Aux:passado:definido)-nominal }} \begin{array}{llll}\text { paderè } & \text { va } & \text { mát } & \text { sáp } \\ \text { morder } & \frac{\text { nominlzn:concreta }}{\text { casa }}\end{array}$

(a) 'a casa da pessoa que a cobra mordeu' ('pessoa' sendo o núcleo interno);

(b) 'a casa da cobra que mordeu a pessoa' ('cobra' sendo o núcleo interno);

(c) 'a casa onde a cobra mordeu a pessoa' (sem núcleo interno).

No exemplo (23), não há núcleo interno e o núcleo externo não tem contraparte dento da cláusula. Notase que a tradução é dada como cláusula complemento ao invés de cláusula relativa.
(23)
bolíp igí ó-ga-néè
peixe tirar 1s-(Aux:passado:definito)-ir-nominal
méne
kázóp
'Sinal de que eu fui pescar'
nominlzn:abstrata sinal

\section{DISCUSSÃO}

Evidentemente, a língua dos Gavião não tem uma construção que especificamente forme cláusulas relativas. As nominalizações sintáticas são construções bem gerais que se traduzem como cláusulas relativas com

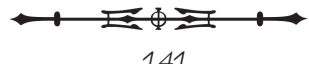


núcleo, cláusulas relativas sem núcleo ou cláusulas complementos. A sua composição é simples, em que N' é um nome sintático (barra-um), S' é uma cláusula encaixada, [+NOM] indica que o tipo funcional da cláusula é nominal (marcado por //-néè// no auxiliar). A sua regra de composição é:

$\mathrm{N} \rightarrow\left\{\begin{array}{c}\mathrm{SV} \\ \mathrm{S} \\ {[+\mathrm{NOM}]}\end{array}\right\}-\left\{\begin{array}{c}\text { mát } \\ \text { méne }\end{array}\right\}$

Em linguagem comum, a regra diz que uma das possibilidades de compor um nome sintático é por meio de um sintagma verbal ou de uma cláusula nominal com uma das duas partículas em seguida. Esse nome sintático, como qualquer nome, pode modificar um radical de nome que o suceda, como nos exemplos (9) e (10), formando um outro nome sintático maior. $\bigcirc$ nome sintático pode também ser o núcleo de um sintagma nominal sozinho. Uma conseqüência dessa simplicidade é a ambigüidade demonstrada em (22a-c). Essa ambigüidade pode ser reduzida através do uso de núcleos externos como em (18).

Uma definição de cláusula relativa restritiva é encontrada em Givón (1990): "A relative clause codes a proposition one of whose participants is coreferential with the head noun that is modified by the clause". Esta definição parece eliminar todas as construções nos exemplos acima, exceto as que têm núcleos externos e internos, mesmo aquelas que têm núcleos internos óbvios, já que seria estranho dizer que o núcleo interno é modificado pela cláusula da qual é um argumento e da qual não foi extraído. $O$ efeito da nominalização sintática é, mais precisamente, dar uma distribuição nominal ao material sintático representado pelos SVs e cláusulas nominalizadas. A questão de núcleo interno é uma questão de interpretação no contexto e não da estrutura da construção.

Segundo uma definição de cláusula relativa menos eurocêntrica, na terminologia de Keenan (1985), as nominalizações sintáticas sem núcleo externo, mas com núcleo interno, seriam o que ele chama de cláusulas relativas internas ( internal RCS). Tipologicamente, as construções Gavião compartilham duas propriedades com as cláusulas relativas internas de Keenan: ocorrem em línguas SOV e não apresentam marcação explíita de núcleo interno. Keenan não menciona cláusulas sem núcleo interno ou externo, do tipo (11) ou (17). Tipicamente, estas se traduzem como cláusulas complementos quando são abstratas e têm um núcleo externo abstrato, como em (23), ou são objetos de verbos que tomam objetos abstratos, por exemplo, 'querer (que)' ou 'esperar (que)'.

\section{NOTAS SOBRE SÍMBOLOS}

Os símbolos $c$ e $j$ indicam africadas palatais e $s$ e $z$ indicam africadas dentais. $O$ símbolo $v$ representa um fricativo bilabial sonoro. $\mathrm{O}$ apóstrofe indica o segmento oclusivo glotal. Vogais prolongadas são indicadas como seqüências, com /'/ marcando tom alto, $/ \wedge /$ marcando tom subindo e / ' / indicando tom alternante. Tons baixos não são marcados. Citações são marcadas com " " e ". Nasalização vocálica está indicada com cedilha. Todos os exemplos são de textos, exceto os últimos quatro, que foram checados com pelo menos dois consultores.

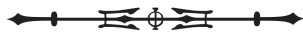




\section{REFERÊNCIAS}

COMRIE, Bernard; HORIE, Kaoru. 1995. Complement Clauses versus Relative Clauses: some Khmer evidence. In: ABRAHAM, Werner; GIVÓN, Talmy; THOMPSON, Sandra (Ed.). Discourse Grammar and Typology. Amsterdam: John Benjamins. Papers in Honor of John W. M. Verhaar.

GIVÓN, Talmy. 1990. Syntax: a functional typological introduction. Amsterdam: John Benjamins. v. 2.

KEENAN, Edward L. 1985. Relative Clauses. In: SHOPEN; Timothy (Ed.). Language Typology and Syntactic Description: complex constructions. Cambridge: Cambridge University Press. v. 2.

KEENAN, Edward L.; COMRIE, Bernard. 1977. Noun Phrase Accessibility and Universal Grammar. Linguistic Inquiry, v. 8, p. 63-100.

MOORE, Denny. 1984. Syntax of the Language of the Gavião Indians of Rondônia (Brazil). Tese (Doutorado em antropologia) - City University of New York, Nova York.

MOORE, Denny. 1989. Gavião Nominalizations as Relative Clause and Sentential Complement Equivalents. IJAL, v. 55, n. 3, p. $309-325$.

NOONAN, Michael. 1985. Complementation. In: SHOPEN, Timothy (Ed.). Language Typology and Syntactic Description: complex constructions. Cambridge: Cambridge University Press. v. 2.

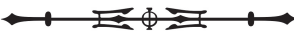

